\title{
DO INDIVIDUAL AO COLETIVO: POSSIBILIDADES DO MOVIMENTO DA PESQUISA DOS PESQUISADORES DA REGIÃO SUL
}

\author{
INDIVIDUAL AND COLLECTIVE: RESEARCH MOTION POSSIBILITIES \\ OF SOUTH REASERCHERS \\ DEL INDIVIDUAL A LO COLECTIVO: POSIBILIDADES DEL MOVIMIENTO DE LA
INVESTIGACIÓN DE LOS INVESTIGADORES DE LA REGIÓN SUR
}

Joana Paulin Romanowski* joana.romanowski@gmail.com

\begin{abstract}
REVISTA PEDAGÓGICA
Revista do Programa de Pós-graduação em Educação da Unochapecó | ISSN 1984-1566

Universidade Comunitária da Região de Chapecó | Chapecó-SC, Brasil Como referenciar este artigo: ROMANOWSKI, J. P. Do individual ao coletivo: possibilidades do movimento da pesquisa dos pesquisadores da região sul. Revista Pedagógica, Chapecó, v. 17, n. 36, p. 14-29, set./dez. 2015.
\end{abstract}

\begin{abstract}
RESUMO: O artigo focaliza o movimento da pesquisa e dos pesquisadores da região sul com o propósito de discutir as possíveis relações entre pesquisa e pesquisadores e a área da educação. Para isso realiza mapeamento dos pesquisadores e seus objetos de pesquisa tomando por referência os pesquisadores bolsistas produtividade.. Na discussão destaca possibilidades e demandas da pesquisa em educação considerando as investigações feitas individualmente e suas possíveis relações com coletivo. Ancora-se na literatura sobre estudos biográficos e o contributo social da pesquisa. Destaca como possibilidades da pesquisa e dos pesquisadores: (i) a formação de pesquisadores e de professores; (ii) a produção da ciência na área da educação; (ii) inserção da pesquisa na constituição da categoria docente; pela participação ativa dos pesquisadores em sociedades acadêmicas e de pesquisa. (iv) intervenção nas políticas públicas.
\end{abstract}

Palavras-chave: Pesquisadores em Educação. Bolsa produtividade em pesquisa. Contribuição da pesquisa. Estado da Arte.
ABSTRACT: The article focuses on the movement of research and researchers in the southern region with the purpose of discuss the possible relations between research and researchers and the education area. It carries out mapping of researchers and research subjects with reference to the research productivity fellows. In discussion highlights possibilities and demands of educational research considering the investigations conducted individual and their possible relations with collective. It builds on the biographical literature on studies and the social contribution of research.

Highlights how possibilities of research and researchers: (i) the formation of researchers and teachers; (ii) the production of science in education; (ii) inclusion of research in the constitution of the teaching category; the active participation of researchers in academic societies and research. (iv) intervention in public policy.

Keywords: Researchers in Education. Research productivity purce. Contribution of research. State of the art.

RESUMEN: El artículo se centra en el movimiento de investigación y los investigadores en la región sur con el fin de discutir los posibles vínculos entre la investigación y los investigadores y área de la educación. Realiza mapeo de los investigadores y los sujetos de la investigación en relación con la beca productividad de la investigación. En la discusión se destacan las posibilidades y exigencias de la investigación educativa teniendo en cuenta las investigaciones realizadas de forma individual y sus posibles relaciones con colectiva. Está basado en la literatura biográfica sobre los estudios y la contribución social de la investigación. Fuera como las posibilidades de investigación y los investigadores: (i) la formación de investigadores y docentes; (ii) la producción de la ciencia en la educación; (ii) la inclusión de la investigación en la constitución de la categoría de la enseñanza; la participación activa de los investigadores en las sociedades académicas y de investigación. (iv) la intervención en la política pública.

Palabras clave: Investigadores en Educación. Becas de productividad de Investigación. Contribución de la investigación. Estado del Arte. 
" Professora Titular da PUCPR, colaboradora do UNINTER, Bolsista Produtividade 2 CNPQ, Doutorado em Educação USP.

\section{INTRODUÇÃO}

Este artigo toma como ponto de partida os objetivos indicados para a elaboração da chamada do dossiê pensamento pedagógico da região sul: recuperando autobiografias, biografias, legados e contributos para a educação brasileira, com a finalidade de colocar em debate a relação sujeito e produção científica do coletivo desses sujeitos. Essa relação assume múltiplas possibilidades de abordagem: o sujeito a partir de sua biografia, o sujeito objetivado pela expressão de sua pesquisa, o sujeito institucionalizado considerando as condições em que se efetiva sua história de vida, o sujeito e os grupos de pesquisa, o sujeito e o coletivo. No exame da pesquisa realizada por esse sujeito e os grupos é possível apontar a articulação da pesquisa no contexto das tendências de investigação em educação, o movimento de articulação entre a pesquisa local e universal, as possibilidades do contributo social da pesquisa. Considerando, portanto, essas questões, o propósito é examinar algumas dessas questões no movimento da pesquisa e dos pesquisadores da região sul focalizando as possíveis relações entre pesquisa e pesquisadores e a área da educação.

Como metodologia realiza estudo do tipo estado da arte, numa perspectiva cartográfica, a respeito dos pesquisadores e da pesquisa em educação. Como indicadores situa quantitativamente os pesquisadores a partir do quadro de concessão de bolsa produtividade em pesquisa pelo $\mathrm{CNPq}$, o volume de pesquisa na região tomando a pesquisa como articulação institucionalizada direcionada à sua contribuição social no cumprimento das finalidades sociais da universidade. A pesquisa e seus atores, descontadas as idiossincrasias, busca produzir, criar, avaliar e disseminar o conhecimento e o saber. As finalidades assumem possibilidades de investigar para solucionar e resolver problemas, para compreender as relações sócio-históricas visando à transformação da realidade, constituir a ciência em determinado campo pela geração do conhecimento, organizado, sistemático e válido, o exercício da crítica pelo questionamento crítico e criativo, como indica André (2001). Streck e Adams (2012, p. 246-247) argumentam considerando outros analistas, que o movimento de investigação realizada na América Latina se caracteriza como:

(1) uma produção intencionada de conhecimento; (2) uma produção coletiva de conhecimento; (3) o reconhecimento da complexidade das práticas de ação social; (4) a reconstrução da prática em sua densidade por meio da recuperação da história, da memória coletiva; (5) a interpretação crítica da lógica e dos sentidos que constituem a experiência; (6) para além dos alcances cognitivos, a busca por melhorar a própria prática, visando gerar as mudanças necessárias que potencializem a eficácia social e a riqueza cultural da experiência. 
Com efeito, tomar decisões e avaliar coletivamente para compreensão das práticas e experiências humanas a partir do rigor crítico científico investigativo se apresentam como demandas para os pesquisadores na realização da investigação.

Na perspectiva de considerar a cartografia dos programas de pós-graduação da região, dos pesquisadores e das tendências da pesquisa, é possível entender que as práticas de pesquisa se associam à experiência vivida pelo(s) sujeito(s), estabelecida em diálogo entre o evento e o conceito, o ser social e a consciência social, isto é, a busca de interação com as evidências, ressaltando seu caráter sócio-histórico (THOMPSON, 1981).

Para situar os sujeitos e a pesquisa foram feitas consultas no CNPq localizando os pesquisadores e sua instituição, bem como os programas de pós-graduação, considerando as linhas de pesquisa e também consulta aos currículos lattes identificando os temas pesquisados por eles. Entende na composição e sistematização dos dados as proposições de Sanchez Gamboa (2007, p. 101) de que as análises quantitativas e qualitativas "se dão como resultado dos processos de análise, síntese, e do movimento" em que "a compreensão e a explicação não são apenas processos intelectualmente conexos, mas sim um só processo, simplesmente referidos a dois níveis diferentes, mas articulados, na construção do objeto". Assim, o processo compreensivo coteja os dados e indicadores com a literatura para compor as inferências provisórias, entendendo que este artigo é uma possibilidade introdutória à discussão com "o intuito de trazer para a reflexão as produções dos intelectuais da Região Sul” em diálogo com a pesquisa na área da educação.

\section{DA BIOGRAFIA DO PESQUISADOR AO COLETIVO NA PESQUISA}

A possibilidade de considerar a pesquisa e pesquisadores ao estabelecer relação com estudos biográficos e o contributo social da pesquisa constitui o construto de abordagem do texto. Desse modo, parece necessário apontar indicadores sobre os propósitos desse tipo de estudos, sem pretensão de aprofundar a questão. Para Arfuch (2010), o estudo biográfico remete à singularidade na sua relação com o mundo, os sujeitos são atores sociais, "uma cartografia da trajetória individual sempre em busca de seus traços coletivos" (ARFUCH, 2010, p. 15). Ao focalizar o sujeito, ainda que na interlocução com o coletivo, a narrativa pessoal vivencial, não está isenta de voyerismo, de usos funcionais e de busca de estratégias de mercado, alerta Arfuch ( 2010). A esse respeito, Silva (2009, p. 163) adverte que o biografismo está relacionado "com o individualismo, os aspectos formais e literários dessa forma de narrativa, suas ligações com a indústria cultural, entre sentenças seguras sobre seus muitos vícios e poucos méritos”. 
Ao focalizar neste texto a relação da pesquisa e do(s) pesquisador(es), essa advertência assume importância, especialmente, ao considerar que ao abordar pesquisadores da região sul "a biografia refere-se não aos comuns, mas sim a um sujeito privilegiado e distinguido, cujo destaque é dado por grupos específicos da sociedade que controlam ou delimitam o fluxo dos acontecimentos - seja ele o biografado ou o biógrafo" ( SILVA, p. 10).

A pretensão é de que a abordagem se distancie da "tradição do biografismo brasileiro vinculado a uma humanização da história e a criação de uma pedagogia moral e cívica" (SILVA, 2009, p. 153) para se direcionar à discussão sobre os vínculos sociais e históricos que se relacionam com a forma como os pesquisadores se vinculam com diferentes grupos e movimentos, priorizando apontar a sua articulação com as tendências da pesquisa quanto as suas temáticas. Com efeito, examinar o(s) pesquisador(es) envolve as instituições e sua produção científica de modo a relacionar a construção da identidade aos critérios de aceitabilidade, de admissibilidade, de credibilidade, e através da constante negociação direta com os outros (POLLAK, 1989, p. 205). Contudo, é pertinente ressalvar que os pesquisadores estão envolvidos em luta "propriamente simbólica para imporem a definição do mundo social mais conforme os seus interesses, e imporem o campo das tomadas de posições ideológicas reproduzindo em forma transfigurada o campo das posições sociais", como discute Bourdieu (1998, p. 11). A pesquisa não isenta da possibilidade de

conduzir esta luta quer diretamente, nos conflitos simbólicos da vida quotidiana, quer por procuração, por meio da luta travada pelos especialistas da produção simbólica (produtores a tempo inteiro) e na qual está em jogo o monopólio da violência simbólica legítima [...], quer dizer, do poder de impor - e mesmo inculcar - instrumentos de conhecimento e de expressão (taxionomias) arbitrários - embora ignorados como tais - da realidade social. (BOURDIEU, 1998, p. 11-12).

Nessa perspectiva, Silva (2009, p. 163-4) coloca em discussão os estudos biográficos em que os "os limites da ideia de verdade e de representação, o papel social do mito, as relações entre público e privado, as ligações entre a narrativa e sua época, entre diversas outras", sobre três vertentes: (a) "uma biografia supõe a ampla utilização de forças sociais pela manutenção de uma memória, ou de um certo tipo de memória, no qual um indivíduo é não somente uma unidade, mas parte de um grupo e representação de ideais e expectativas que já não são subterrâneas, mas que convivem junto a outras manifestações de superfície); 


\footnotetext{
${ }^{1}$ Entendemos que pesquisadores não bolsistas realizam pesquisa de alta contribuição social, portanto, no limite deste texto a referência ao CNPq respeita o coletivo, ainda que privilegie um grupo.

${ }^{2}$ De acordo com dados do CNPq, em 2006 totalizavam 9.066 bolsas correspondendo a $16 \%$ para 57.586 doutores. Em 2000 o percentual de bolsas era de $27 \%$, ou seja, o aumento número de bolsas não é na mesma proporção que o aumento da titulação.
}

(b) se encararmos o pesquisador "como notável e por si só é visto como diferenciado dentro do grupo e da sociedade da qual faz parte, não representando, a priori, grupos marginalizados, silenciados, minoritários, também está situado em um campo de disputa no qual memória e esquecimento também se estabelecem em relação a sua trajetória de outros de seu mesmo grupo"; (c) "uma mesma matéria narrativa, uma trajetória individual, pode assumir em diferente obras/ autores/ épocas" uma pluralidade de significados.

As biografias dos pesquisadores constituem o foco do artigo aqui proposto como já dito, contudo, a indicação de dados sobre pesquisadores da região sul tangencia um corpus de vozes plurais nas quais se expressam as suas histórias de vida demarcadas pelas diferenças e recorrências. Diferenças "numa sociedade em que o trabalho produtivo" consome as existências, em que o resgate do singular pode resgatar a unicidade de cada vida. Recorrências que permitem a inclusão de pertença a uma mesma história constitutiva do "nós" (ARFUCH, 2010, p. 349).

O exame dos pesquisadores neste artigo considera como indicadores os dados a respeito dos bolsistas de produtividade em pesquisa do CNPq, por ser a bolsa concedida aos pesquisadores que se destaquem entre seus pares, valorizando sua produção científica segundo critérios normativos, estabelecidos pelo CNPq, e específicos, pelos Comitês de Assessoramento (CAs) do CNPq. Portanto, a concessão de bolsa inclui um processo de apreciação e decisão coletiva, o que pode ser um critério para o exame da pesquisa e de pesquisadores ${ }^{1}$. Somam em educação, um total de $388^{2}$ bolsistas de produtividade em educação, distribuídos por categoria e nível. Os pesquisadores agraciados com a bolsa produtividade na região sul são 108, o que corresponde a 27,8\% do número de bolsas da área de educação. A distribuição por instituição indica que as universidades federais são as que possuem maior número de bolsistas de produtividade, seguidas pelas instituições comunitárias (PUCs) e estaduais, e com menor número as instituições privadas. A Figura 10.1 contém gráfico que permite visualizar a distribuição do número de bolsistas por instituição. A distribuição de maior número de bolsas nas instituições públicas pode ser compreendida na perspectiva histórica, os programas de pós-graduação antecedem os das demais instituições. A criação de curso de doutorado nessas instituições segue a mesma lógica, data de 1976 o da UFRGS, posteriormente em 1994 o da UFSC e em 2001 o da UFPR (ROMANOWSKI, 2012). 


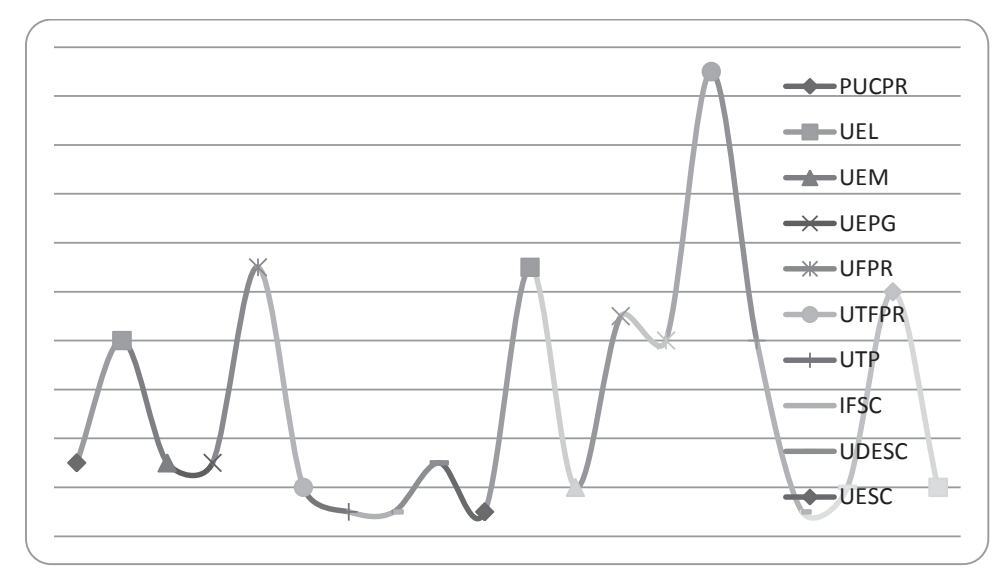

Figura 1 - Distribuição do número de bolsas por instituição - região sul Fonte: A autora com base em dados disponíveis no $\mathrm{CNPq}$

De acordo, com os critérios do CNPq é definida essa distribuição com os critérios de: a) produção científica do candidato; b) formação de recursos humanos em nível de Pós-Graduação; c) contribuição científica e tecnológica e para inovação; d) coordenação ou participação principal em projetos de pesquisa, e e) participação em atividades editoriais e de gestão científica e administração de instituições e núcleos de excelência científica e tecnológica. Isso indica que o pesquisador bolsista realiza atividades para além da investigação, é docente pesquisador, orienta, assume funções administrativas, enfim realiza todas as atividades inerentes aos professores da educação superior, como analisam Veiga e Zabalza. Para Zabalza (2004) são três funções aos professores universitários: o ensino (docência), a pesquisa e a administração em diversos setores da instituição, as quais Veiga (2010) acrescenta a de orientação acadêmica como monografias, dissertações e teses, portanto formadores de formadores. Zabalza (2004) aponta que, além disso, na atualidade os pesquisadores buscam "financiamento, negociação de projetos e convênios com empresas e instituições, assessorias, participação como especialistas em diversas instâncias científicas", o que implica em estabelecer e participar de redes e associações de pesquisa nacionais e internacionais colocando a pesquisa em novo patamar. Um novo paradigma de inter-relação e transformação do conhecimento se anuncia. O conhecimento individual supera-se pela inclusão do sujeito e sua produção em totalidade no grupo, a produção do grupo supera-se pela inclusão dos sujeitos, e os grupos colocados em rede universalizam o conhecimento em constante transformação, ou seja, o local compõe-se com o universal e o universal compõe-se com o local.

$\mathrm{Na}$ perspectiva de situar os pesquisadores em relação ao campo de investigação, o exame com base nos dados da CAPES dos programas de pós-graduação na região sul indica a existência de 159 programas, dos quais 60 ofertam mestrado acadêmico, $33 \mathrm{com}$ mestrado profissional e 66 ofertam mestrado e doutorado. Em estudo que examina 
101 grupos de pesquisa da região sul, Robl e Meneghel (2003), consideram 229 linhas de pesquisa, 686 pesquisadores e 615 estudantes.

Ao investigar as linhas de pesquisa dos programas de pós-graduação, mestrado e doutorado - PPGE, aos quais os bolsistas de produtividade pertencem, verifica-se um total de 72 linhas de pesquisa. A maioria dos programas centra-se em duas a quatro linhas, com exceção do PPGE da UFGRS que mantém três eixos abrangendo várias linhas de pesquisa. As linhas recorrentes abordam ensino e aprendizagem associados a conhecimentos específicos como ciências, arte e linguagem, modalidades de ensino como educação especial e infantil, cultura associada à linguagem e ensino, formação de professores, tecnologias e comunicação, história da educação, filosofia da educação, prática docente, políticas educacionais. Linhas menos abordadas focalizam sociologia educacional, cognição e aprendizagem, educação e trabalho. São indicados como linhas singulares estudos sobre currículo, sexualidade e gênero, infância, movimentos sociais, ética. Muitas das linhas estabelecem associação entre objetos de estudo como formação e prática docente, linguagem e tecnologia, cultura e formação docente, políticas e gestão educacional, ética, alteridade e linguagem. Os focos das linhas de pesquisa indicam temas como tecnologias, formação de professores, educação inclusiva, diversidade, mas também a intensificação de estudos na perspectiva da história e historiografia e estudos culturais. $\mathrm{O}$ ensino é focalizado associado à aprendizagem e aos conhecimentos específicos, bem como a prática e as políticas educacionais.

Ao consultar as publicações dos pesquisadores, investigação realizada por meio de consulta à plataforma lattes, verifica-se uma diversificação intensa de assuntos, temas, campos disciplinares, inseridos na área da educação. Muitos projetos e publicações assumem abordagem interdisciplinar, focalizando a sociologia e a educação, filosofia e educação, psicologia e educação, meio ambiente e educação, entre outros. Esses campos disciplinares são consolidados na área.

Entre os assuntos pesquisados na perspectiva da escolarização: a educação infantil, analfabetismo/alfabetização, escolarização, letramento, escrita e leitura, ensino médio, educação superior, educação no campo. Na perspectiva do ensino e da organização escolar: química e meio ambiente, educação em Ciências, educação matemática, o ensino de física, literatura infantil, currículo escolar. Quanto à relação professor e alunos a indisciplina escolar. Nos campos disciplinares se destacam os estudos em história da educação, considerando as instituições educacionais, a cultura escolar, práticas de leitura, escrituras de foro privado, estudos dos manuais, estudos sobre os intelectuais, concepções em história da educação; estudos em didática. E mais, os estudos em psicologia da educação, sociologia da educação, sociologia da cultura e do esporte, filosofia da 
educação. No campo da política educacional são estudos em diferentes perspectivas como integração da educação superior, benchmarking e meta-regulação, relação educação, estado e sociedade, políticas para a educação básica, em formação de professores e na avaliação. Além disso, estudos sobre educação e trabalho. No campo da formação de professores investigações sobre a formação inicial, a inserção profissional, a formação continuada, formação do professor para a educação básica e para a educação superior. Em relação às tecnologias e da comunicação há intensificação de estudos sobre informática na educação, no ensino de disciplinas como física, alfabetização, na educação especial, inclusão digital, acessibilidade, avaliação de redes de colaboração e pesquisa, comunidades de aprendizagem, estética do virtual e autoria coletiva, mídia e subjetividade, cinema e infância. Estudos em assunto singulares como sexualidade e gênero, igreja católica e educação, ética e subjetividade, educação e estética, educação e justiça social. Nos estudos de educação não formal, educação permanente, envelhecimento, velhice, educação de jovens e adultos, a relação entre educação e psicanálise, educação de surdos, estudos das crianças, da infância.

As abordagens teórico-metodológicas incluem pesquisas na perspectiva do materialismo histórico dialético, das representações sociais, interlocução com análises psicanalíticas, teorias contemporâneas pós-estruturalistas, escola de Frankfurt, complexidade. Os tipos de estudo incluem análises críticas, interpretativas e compreensivas, avaliações, pesquisa participante e pesquisa ação, estado da arte, entre outras. A abordagem predominante é a qualitativa.

Trata-se de um mapa composto na diversidade em que se expressa a prática da pesquisa educacional tanto em relação aos assuntos investigados como em relação às vertentes teórico-metodológicas. Esses pesquisadores atuam em diferentes possibilidades de promoção da educação, pois como sujeitos históricos, produzem e são produzidos, no contexto das condições em que se situam e em que atuam.

\section{POSSIBILIDADES E DEMANDAS DA PESQUISA EM EDUCAÇÃO: DO INDIVIDUAL AO COLETIVO}

Entre as possibilidades de contribuição e atuação profissional dos pesquisadores destacam-se as seguintes perspectivas: (i) na formação de pesquisadores e de professores elevando o estatuto da qualificação profissional da categoria. (ii) na produção da ciência na área da educação, pois as pesquisas possibilitam a compreensão da prática educacional não só pelo acúmulo de conhecimento acumulado na área, e sim pela teoria pedagógica decorrente dos estudos e pesquisas da prática. (ii) inserção na constituição da categoria docente pela participação ativa dos pesquisadores em sociedades acadêmicas e de pesquisa. 
${ }_{3}$ Um dos propósitos do mestrado profissional é a formação dos professores da educação básica. (iv) intervenção nas políticas públicas, indicações, sugestões e participação na proposição e gestão de projetos educacionais, bem como na definição de metas para o sistema educacional, local e nacional.

$\mathrm{Na}$ análise das possibilidades de contribuição dos pesquisadores na formação de profissionais da educação, quantitativamente verifica-se uma elevação e expansão de professores mestres $(38,9 \%)$ e doutores $(31,7 \%)$ de acordo com dados de 2012, superando o índice de exigência estabelecido em 1996. Na perspectiva da educação básica os índices de formação dos professores em pós-graduação não aparecem nos resumos técnicos dos censos realizados pelos INEP. Contudo, a existência de estatutos de carreira docente que incluem este nível de formação como um dos estrados de ascensão profissional é indicativo dessa formação entre os professores da educação básica (ROMANOWSKI, 2012). Além disso, pesquisas que caracterizam o nível de formação de profissionais da educação básica apontam que os professores tem buscado a formação em mestrado e doutorado. ${ }^{3}$

Ainda, tomando por referência Werle (2012), que realiza exame das interlocuções da pós-graduação com a educação básica, a autora destaca entre os pontos de interlocução os profissionais envolvidos tanto na orientação para a pesquisa como na docência. Nas ações realizadas pelos pesquisadores quanto à formação as possibilidades se expressam de modo direto na orientação para a pesquisa de alunos de graduação em programas de iniciação científica, trabalhos de conclusão de curso e mesmo na docência de disciplinas. Essa atuação se replica nos programas de pós-graduação na formação de mestrandos e doutorandos. A pesquisa no processo de formação para Cochram-Smith e Lytle (1999) é fundamental para o desenvolvimento profissional do professor. Segundo essas autoras, a pesquisa favorece o desenvolvimento do professor como agente de mudança e de produção da teoria crítica em educação. Os professores, ao realizarem pesquisa apreendem e aprendem processos de produção do conhecimento, de questionamento de sua própria prática, para o desenvolvimento de uma atitude investigativa, autônoma, criativa e comprometida (CORTELAZZO; ROMANOWSKI, 2007, p. 17).

Sobre a pesquisa, como processo de formação, inúmeros pesquisadores apontam suas possibilidades como André (2001); Ludke (2004); Tardif, e Zourhal, (2005); Cunha $(2013,2015)$. Segundo Cunha (2013, p. 611) "a pesquisa acompanha os movimentos político-econômicos e socioculturais que dão forma ao desempenho docente, quer no plano real, quer no ideal". Com efeito, entre as possibilidades do processo de formação de pesquisadores cabe destacar que a formação se irradia, isto é, o professor pesquisador vai envolver outros professores e mesmo seus alunos, e esses, por sua vez, suas famílias, um efeito em cascata de melhoria da educação como prática social. O efeito como possibilidade ocorrerá pela intensificação da 


\footnotetext{
${ }^{4}$ Soma 54.617 defesas, entre 1987 a 2012, conforme levantamentos realizados com base no banco de resumos e dissertações da CAPES ( ROMANOWSKI, 2013).
}

causa em que a pesquisa, ao envolver a compreensão da prática educativa, origina probabilidade de novas opções e escolhas de intervenções nessa prática. Essas intervenções são geradas com menor grau de tentativas do tipo ensaio e erro, pois emergem da análise compreensiva.

Quanto a possibilidades da pesquisa na produção da ciência na área da educação, historicamente, inúmeros pesquisadores têm realizado análises críticas, entre os quais Gouveia (1971), Warde (1990), Goergen (1985), Cunha (1991), Saviani (2012), Gatti (2001), Bittar (2009), André (2006), Campos (2009). Ao apontar esses autores não cabe trazer uma síntese de suas críticas e ponderações sobre questões que envolvem, entretanto, parece pertinente retomar André (2006) que, ao realizar um balanço da pesquisa na área da educação, destaca que "houve grande crescimento no número de trabalhos e mudanças nos temas, nos enfoques, nas metodologias e no contexto de produção", destacando a implantação dos cursos de pós-graduação como propulsor desse rápido crescimento. Em termos de número de teses e dissertações, o quantitativo expressa esse crescimento, pois em 1987 constam 11 teses e dissertações defendidas na área de educação e em 2.012 esse quantitativo atinge 3.817 defesas ${ }^{4}$.

Para além do quantitativo, Chalot (2006, p. 9) chama atenção sobre pesquisadores em educação que "qualquer que seja sua origem acadêmica, se interessam fundamentalmente pela questão da educação" observando aquilo "que ela tem de específico, e, de outro lado, aos efeitos da pesquisa sobre a educação", portanto, ao atuarem na área transitam entre "conhecimentos (por vezes de origens diversas), práticas e políticas". De outra perspectiva, Correa e Leite (2011) enfatizam que "o campo da educação focalizou, num primeiro momento, o debate da prática de pesquisar fenômenos educacionais em questões metodológicas e técnicas (GATTI, 2002), desconsiderando a construção do estatuto epistêmico e histórico da ciência”. Isso tem gerado demandas permanentes na compreensão do estatuto epistemológico da educação, além da melhoria necessária do próprio estatuto da pesquisa. Uma terceira vertente crítica aponta para a existência de um acúmulo considerável de produção realizada pelos pesquisadores, mas que tem se mostrado insuficiente para melhoria da prática educacional, pois permanentemente novas demandas são instauradas na prática educativa, além do que a pesquisa educacional assume mais uma perspectiva explicativa, compreensiva e crítica do que intervencionista (CAMPOS, 2006).

Na inserção na constituição da categoria docente pela participação dos pesquisadores em sociedades acadêmicas e de pesquisa é possível destacar que associações e sociedades de pesquisadores são consolidadas no Brasil. Além disso, dadas as demandas infindáveis de novas problemáticas, novos grupos de pesquisadores se articulam compondo formas de colaboração e articulação. Para situar a compreensão de comunidade científica toma-se por referência 
as proposições de Kuhn (1977, p. 356), pois se refere a uma comunidade científica como um grupo de praticantes de uma especialidade científica, que se encontram unidos por elementos comuns que foram incorporados através da iniciação científica. Com efeito, em uma comunidade científica os cientistas veem-se a si mesmos e são vistos pelos outros como os responsáveis pela produção científica, culminando na resolução de problemas em produção da ciência. Destaca o autor que a comunidade científica possibilita legitimidade à prática científica contribuindo para o desenvolvimento da ciência. Esse é um espaço aberto, pois uma comunidade científica, segundo Durkheim (2008), articula-se à questão da solidariedade social. A intensificação de suas ações no interior da sociedade origina seu prestígio e reconhecimento social. Isso implica que os indicadores gerados na pesquisa possam ser considerados na definição de metas e prioridades no sistema educacional e nos rumos da própria pesquisa.

Quanto à relação entre a pesquisa e as definições de políticas públicas, Campos (2009) aponta a pouca existência de práticas nesta perspectiva. Ressalta a autora que movimentos internacionais buscam romper com essa inércia de modo a implementar "práticas políticas baseadas em evidências". Esse processo consiste em realização de pesquisas que permitam perceber quais as possibilidades de intervenção de modo adequado na solução de questões adequadas. Adverte a autora sobre os limites de realização da pesquisa nesta perspectiva, pois as escolhas e interpretações não são isentas de vieses, que podem privilegiar tendências momentâneas, nem todos passíveis de operacionalização, pois "critérios para julgar uma prática educativa nem sempre são unicamente técnicos". Ressalta que "a pesquisa não pode fornecer respostas prontas aos sistemas de ensino. Seus resultados constituem elementos importantes a serem levados em conta nas decisões, mas não são os únicos e nem podem ser incorporados sem mediações" (CAMPOS, 2009, p. 281) Contudo, um diálogo entre pesquisadores e gestores pode resultar em possibilidades de decisões mais ponderadas.

Nesse sentido, ao considerar a intervenção da pesquisa e dos pesquisadores nas políticas públicas com indicações, sugestões e participação na proposição e gestão e projetos educacionais, bem com na definição de metas para o sistema educacional, local e nacional, é possível lembrar o artigo de Souza e Bianchetti (2007) que analisa as contribuições da ANPEd nesta direção. Dizem os autores que os pesquisadores

mesclam protagonismos de pessoas e do coletivo da associação, que se fizeram e se fazem presentes em momentos marcantes da história da pós-graduação em educação - interferindo inclusive na discussão e elaboração dos planos nacionais de pós-graduação e nos movimentos por uma educação de qualidade, pela redemocratização da educação. 
Cabe destacar as mobilizações de discussões para a Constituinte, no processo de elaboração da Lei de Diretrizes e Bases da Educação Nacional, do Plano Nacional de Educação e das Diretrizes Curriculares Nacionais. Essa mobilização envolve diretamente os pesquisados quando indicados para participar de comissões para proposição e implementação de políticas, no processo de composição dos membros para o Conselho Nacional de Educação (CNE). Os autores incluem também a seguinte relação: "a permanente busca do rigor da realização da pesquisa nos programas de pós-graduação imprime o caráter de luta de validade e credibilidade dos resultados obtidos na pesquisa” (SOUZA; BIANCHETTI, 2007, p. 9).

A participação direta de pesquisadores em cargos de gestão educacional constitui-se em espaço de intermediação entre a pesquisa e a intervenção nos processos decisórios, ainda que em instâncias distintas, contudo, esse gestor pesquisador não está isento de contaminação entre a pesquisa e a gestão. Ressalta Gatti (2006, p. 29) a presença de "porosidade entre o que se produz nas instâncias acadêmicas e o que se passa nas gestões e ações nos sistemas de ensino".

O rigor na realização da pesquisa com validade no conjunto das demais ciências de modo a garantir seu estatuto de credibilidade, valoração e reconhecimento permite exercer autoridade social de modo a subsidiar possíveis alternativas para as questões educacionais.

\section{CONSIDERAÇÕES PROVISÓRIAS}

No término deste texto é possível destacar apontamentos resultantes da relação entre o esforço individual dos pesquisadores na realização da pesquisa e a contribuição da pesquisa com a área da educação. Definir uma abordagem coletiva não significa invalidar o reconhecimento desse esforço individual, alvo em outros estudos e produções.

Este texto, ao focalizar pesquisadores e pesquisa na região sul, não desconhece o movimento entre pesquisadores nacionais e internacionais e a intensidade com que a área de educação produz suas análises, críticas e debates na constituição do conhecimento educacional e pedagógico. Desse modo, as indicações a seguir tomam por finalidade a continuidade do debate:

(i) A publicização encetada nos espaços de comunicações entre pesquisadores para oportunizar o conhecimento das pesquisas realizadas em educação favorece a democratização e acesso para a comunidade pública vinculada aos sistemas educacionais. Com efeito, pesquisadores e pesquisa são mostrados, divulgados de modo a tornar o conhecimento um bem comum.

(ii) Os debates em torno da pesquisa em educação, em torno de seu objeto, método, resultados podem constituir elementos orientadores da própria produção na área e corpo de compreensão de condições em 
que se situa o sistema, a prática e o estado da educação nacional.

(iii) Pesquisadores podem apontar prioridades, lacunas, limitações e necessidades a serem consideradas nas políticas públicas, na organização, práticas educativas e na melhoria do estatuto de desenvolvimento profissional dos profissionais da educação. Isso possibilita proporcionar benefícios ao conjunto de condições da vida social que permeiam as condições dos grupos e a cada um dos seus membros.

(iv) Considerar o sujeito, sua história, seus vínculos favorece compreender as condições objetivas nas quais as relações sociais se evidenciam, por heterogeneidade, diversidade, ora como contradições, oposições, ora como produção de novas formas. Trata-se de sujeitos atuantes no curso da história que, por suas ações individuais e coletivas, podem discutir, formular, interferir e implementar novas práticas.

(v) A perseverança pelo estatuto científico e epistemológico da pesquisa, encetado tanto no debate como na prática da pesquisa, focalizada no envolvimento dos pesquisadores em movimentos interiorizados nos programas de pós-graduação e sociedades científicas, expressa que a pesquisa na área educacional assume qualificação no cenário da produção científica.

(vi) A constante comunicação beneficiando interações, intercâmbios, novas composições de parcerias, impulsionando a inserção de pesquisadores, provoca o pluralismo abrigando condições de vida social que permitem aos grupos e a cada um dos seus membros coexistirem na prática da pesquisa, que em primeira instância tem por finalidade desvelar o desconhecido para propiciar a compreensão da realidade.

Enfim, o coletivo de pesquisadores expressa contribuição em diferentes instâncias, entretanto os determinantes sócio-históricos mantêm e exigem permanente esforço na direção da relação de determinado para determinante, de constituídos para constituintes. Isso quer dizer que os pesquisadores podem ter na pesquisa um espaço constante para a crítica, denúncia, luta, sem prejuízo da vigilância do estatuto epistemológico, teórico e denso da produção de ciência.

Ao finalizar este texto, cabe indicar que a sua provisoriedade se expressa no limite da interpretação realizada, mas assume o caráter de penhora para a continuidade de entendimento do campo da pesquisa em educação na compreensão de possibilidade de seus atores.

\section{REFERÊNCIAS}

ANDRÉ, M. (Org.). O papel da pesquisa na formação e na prática dos professores. 2. ed. Campinas: Papirus, 2001. 
ANDRE, M. E. D. A. Pesquisa em Educação: buscando rigor e qualidade. Cadernos de Pesquisa (Fundação Carlos Chagas), São Paulo, v. 113, p. 51-64, 2001.

ANDRÉ, Marli. A jovem pesquisa educacional brasileira. Diálogo Educacional, v. 6, n. 19, p. 11-24, set./dez. 2006.

ARFUCH, Leonor. O espaço biográfico: dilemas da subjetividade contemporânea. Tradução de Paloma Vidal. Rio de Janeiro: EdUERJ, 2010.

BITTAR, Marisa. A Pesquisa em educação no Brasil e a constituição do campo científico. Revista HISTEDBR On-line, v. 33, p. 1-20, 2009.

BOURDIEU, Pierre. O poder simbólico. Rio de Janeiro: Bertrand Brasil, 1998.

CAMPOS, M. M. Pesquisa em educação: algumas questões para debate. Educação \& Linguagem, v. 9, n. 14, p. 4658, jul./dez. 2006

CHARLOT, Bernard. A pesquisa educacional entre conhecimentos, políticas e práticas: especificidades e desafios de uma área de saber. Rev. Bras. Educ., abr. 2006, v. 11, n. 31, p.7-18. ISSN 1413-2478

COCHRAN - SMITH, Marilyn; LYTLE, Susan. Relationships of knowledge and practice: Teacher learning in communities. In: A. Iran-Nejad and C.D. Pearson (Eds.), Review of Research in Education, v. 24, p. 251-307, 1999. Washington, DC: American Educational Research Association.

CORTElaZZO, I; ROMANOWSKI, J. Pesquisa e prática profissional: procedimentos de pesquisa. Curitiba: IBPEX, 2007.

CUNHA, L. A. Pós-graduação em Educação: no ponto de inflexão. Cadernos de Pesquisa, São Paulo: Fundação Carlos Chagas. n. 77, p. 63-67, 1991.

CUNHA, M. I. Conocimientos en redes: los grupos de investigación y las ppsibilidades de producción compartida.. Didáskomai: Revista de Investigaciones sobre la Enseñanza, v. 3, p. 5-17, 2012.

CUNHA, M. I. O tema da formação de professores: trajetórias e tendências do campo na pesquisa e na ação. Educação e Pesquisa (USP. Impresso), v. 39, p. 609-625, 2013.

CUNHA, MARIA ISABEL DA. Investigación y docencia: escenariosy sendas epistemológicas para la evaluación de la educación superior. Revista Digital de Investigación en Docencia Universitaria (RIDU), v. 13, p. 79-94, 2015 . 
CUNHA, MARIA ISABEL DA . Invetigación y docencia: escenariosy sendas epistemológicas para la evaluación de la educación superior. Revista Digital de Investigación en Docencia Universitaria (RIDU), v. 13, p. 79-94, 2015 .

DURKHEIM, E. A divisão do trabalho social. São Paulo, SP: Martins Fontes, 2008.

GATTI, B. A. Implicações e perspectivas da pesquisa educacional no Brasil contemporâneo. Cadernos de Pesquisa. São Paulo: Fundação Carlos Chagas, n. 113, p. 65-62, 2001.

GATTI, Bernadete. A construção da pesquisa em educação no Brasil. Brasília: Plano Editora, 2002.

GOERGEN, Pedro. A pesquisa educacional no Brasil: dificuldades, avanços e perspectivas. Em Aberto, Brasília, n. 31, p. 1-18, jul./set. 1985 .

GOUVEIA, A. J. A pesquisa educacional no Brasil. Cadernos de Pesquisa, São Paulo, v. 1, n. 1, 1971.

KUHN, Thomas. (1973) Objetividade, juízo de valor e escolha teórica. IN: A Tensão Esencial. Lisboa, Edições 70, pp. 383-405, 1977.

LÜDKE, M. et al. O professor e a pesquisa. 3. ed. Campinas: Papirus, 2004. v. 1.

MENEGHEL, S. M. ; ROBL, Fabiane . Produção Coletiva de Conhecimento: os grupos de pesquisa em educação da região sul. Contrapontos (UNIVALI), v. 4, p. 517-531, 2004.

NEVES, Rosa Maria Corrêa das and Leite, Siomara Borba Alguns aspectos para se pensar a pesquisa em educação: o estatuto epistêmico e social da ciência. Contrapontos, Ago 2011, v. 11, n. 2, p.207-214. ISSN 1984-7114

POLLAK, Michael. Memória, esquecimento, silêncio. Estudos históricos, Rio de Janeiro, CPDOC/FGV, v. 1, n. 3, 1989. Disponível em: <http://bibliotecadigital.fgv.br/ ojs/index.php/reh/article/viewArticle/2278/1417>. Acesso em: 6 set. 2015 .

ROBL，F. MENEGHEL,S.M. Produção Acadêmica em Grupos de Pesquisa em Educação - O Perfil dos GPs do Sistema ACAFE/SC. In: Desafios da Educação neste século: pesquisa e formação de professores - Cruz Alta: INICRUZ,2003.

ROMANOWSKI, J. P. Pós-graduação em educação: contribuições para a formação de professores In: A pós-graduação e as interlocuções com a educação básica. 
Edited by Flávia Brochettto Ramos; Neires Maria Soldatelli Paviani; Tânia Maris de Azevedo. 1. ${ }^{\mathrm{a}}$ ed., v. 1, 130-150. Caxias do Sul: UCS, 2012.

ROMANOWSKI, J. P. Tendências da pesquisa em formação de professores In: Atos de Pesquisa em Educação (FURB), v. 8, p. 479-499, 2013.

SÁNCHEZ GAMBOA, S. Pesquisa em Educação: métodos e epistemologias. Campinas: Papirus, 2007.

SAVIANI, D. O Inep, o diagnóstico da educação brasileira e a Rbep. Revista Brasileira de Estudos Pedagógicos, v. 93, n. 234, [número especial], p. 291-322, maio/ ago. 2012.

SILVA, Maria Aparecida de Oliveira. Biografia como fonte histórica. Cadernos de Pesquisa do CDHIS, Uberlandia, n. 36/37, A. 20, p. 9-15, 2007.

SILVA, Wilton Carlos Lima. Biografias: construção e reconstrução da memória. Fronteiras. Dourados, MS, v. 11, n. 20, p. 151-166, jul./dez. 2009.

SOUZA, Sandra; BIANCHETTI Lucídio. Pós-graduação e pesquisa em educação no Brasil: o protagonismo da ANPEd. Revista Brasileira de Educação, Rio de Janeiro, v. 12 n. 36 set./dez. 2007. 389.

STRECK, Danilo R.; ADAMS, T. Pesquisa em Educação: os movimentos sociais e a reconstrução epistemológica num contexto de colonialidade. Educação e Pesquisa (USP. Impresso), v. 38, p. 243-258, 2012.

TARDIF, M.; ZOURHAL, A. Difusão da pesquisa educacional entre profissionais do ensino e círculos acadêmicos. Cadernos de Pesquisa, Fundação Carlos Chagas, São Paulo, v. 35, n. 125, p.13-35, maio/ago. 2005.

THOMPSON, E. P. A miséria da teoria. Rio: Zahar, 1981.

VEIGA, Ilma Passos Alencastro. Alternativas Pedagógicas para a Formação do Professor da Educação Superior. In: Docentes para a Educação Superior: processos formativos. Campinas, SP: Papirus, p.13-28, 2010.

WARDE, M. J. O papel da pesquisa na pós-graduação em educação. Cadernos de Pesquisa, Fundação Carlos Chagas, São Paulo, n. 73, p. 67 - 75, 1990.

WERLE, Flávia. A interlocução entre a pós-graduação e educação básica. CONFERÊNNCIA DE ABERTURA IX ANPED SUL. Caxias do Sul, 2012. [Anotações pessoais].

ZABALZA, M.A. O ensino universitário: seu cenário e seus protagonistas. Porto Alegre: Artmed, 2004. 